\title{
Mechanical Properties of PVA \& Steel Hybrid Fiber Reinforced Concrete
}

\author{
K Sharmila Sai Sree ${ }^{*}$, Srikanth Koniki ${ }^{1}$ \\ *PG student, Civil Engineering Department, GRIET, Hyderabad, India, \\ ${ }^{1}$ Associate Professor, Civil Engineering Department, GRIET, Hyderabad, India,
}

\begin{abstract}
Combining various kinds of fibre to achieve good response and strength from the concrete by using different experiments is shown in this research. Here PVA which is polyvinyl alcohol and HS hooked end steel fibres are used to gain more strength compared with normal concrete or single fibre concrete. Here first we take PVA specimens results by considering optimum dosage $0.15 \%$ result \& HS fibre is taken as HFRC concrete by this the strength of the concrete can control the crack behavior occurred in specimens. Mechanical properties such as compressive strength test, flexure strength, and stress-strain behavior are studied. Combining different fibers HFRC is mainly useful for longstanding structures. This method can be easy to understand and economical.
\end{abstract}

\section{Introduction}

Concrete is broadly used in construction as a material, but its brittleness and crack growth are more so to detect the damage caused in structure different method is used which is structural health monitoring (SHM). Structural health monitoring shows the result which is the life of the structure and characterization techniques for structures like dams, bridges, high raised buildings, wind turbines, and tunnels, etc. several types of sensors are attached to the structure or it can be either in DIC methods, etc. SHM includes installing sensors, data acquisition, data transferring which shows the structure safety, performance, and integrity [1]. SHM monitoring and assessment are very important on time and costeffective maintenance. Data helps to make or maintain a better and realistic structure in the future. maintain good strength in structure fibers are randomly distributed in concrete which is fiber reinforced concrete there are different types of testing's which are continuous testing and periodic testing [2]. The response taken in the structures is static load, dynamic load, and vibrations. By maintaining SHM reduction of repair and encouraging use in innovative materials are also done. Fiber-reinforced concrete is taken to maintain strength in structure and control the brittleness and crack growth. Mono fiber reinforced concrete (FRC) is to maintain good strength of the material [4] and double fibers are also combined and used for the material bond which is called hybrid reinforced concrete (HFRC) [7]. There is a mix of different types of fibers which are metallic and non-metallic fibers such as glass, polyvinyl alcohol, steel, etc. combing of metallic and non-metallic fibers has 3 types of principles which are the use of short and long fibers, homogenous distribution of fibers mix and each fiber should be effectively used [8]. The HFRC plays a crucial role in concrete and acts as a bridge between crack growth and gives good support to the specimen. Here micro-cracks are turned into macro cracks so the fibers combine each other and it controls the breakpoint [9]. This will increase the ductility and tensile strength in the specimen and few conditions, segregation is avoided [9]. In this investigation, the hybrid fibers are PVA and Hooked end steel fibers which are metallic and Non- metallic fibers.

\section{Research significance}

In this study, HFRC is about PVA and HS steel fibers where their length is $12 \mathrm{~mm}$ and $\mathrm{HS}$ fiber is about $25 \mathrm{~mm}$. Combining hybrid fibers the concrete acts as a bridge between the cracks. To shape the HFRC using Matlab software. Matlab software is used for finding the strength of the specimens and to find stress-strain. Shear stress of concrete is developed by the fiber hybridization and advantages of HFRC are taken. In this investigation combination of hybrid fibers which are PVA and Hooked end steel delivers a lot of modifications in mechanical and physical properties such as shape, size, tensile strength, and brittleness, etc. to show the accurate values of HFRC lot of trails are implemented and later particular ratio is taken and executed. To tackle these concerns PVA and Hooked end steel fibers are combined to develop the strength, brittleness, and ductility of HFRC. HFRC enhances the tensile

\footnotetext{
* Corresponding author: kunchesharmila@gmail.com
} 
properties and energy absorption capacity of composite [9].

\section{Experimental study}

\subsection{Materials}

This chapter gives information about the materials used in HFRC specimens. Here the specimens are of different sizes, shapes. Ordinary Portland cement is used, and its grade is 53 validating to the codebook IS- 12269(BIS2013) [10]. Cement has a specific gravity of 3.12 and a consistency of $32 \%$. Mineral admixture flyash class-F is sourced from the local market. Fine aggregate is taken from the river sand considering the codebook IS 383 (BIS- 2016) with a fine modulus is 6.8 and its specific gravity is about 2.68 [11]. Coarse aggregate well crushed graded aggregate is taken according to the codebook IS 383 (BIS- 2016) with fine modulus is 6.8 and specific gravity of coarse aggregate is 2.78 . Superplasticizer chemical is FORSAC Conplast SP430 is used for all mixes. For good workability, Codebook IS 9103 (BIS 2004) is used [12]. Fibers Polyvinyl alcohol (PVA) and Hooked end steel as Metallic fibers are used as shown is fig 1 . Different properties are mentioned below table 1 .

Table 1. Properties of mono fibers

\begin{tabular}{|c|c|c|}
\hline Property & $\begin{array}{c}\text { Hooked end steel } \\
\text { fiber }\end{array}$ & Polyvinyl alcohol \\
\hline Fiber code & SF & PVA \\
\hline Length (mm) & 25 & 12 \\
\hline Diameter (mm) & 0.4 & 0.06 \\
\hline Aspect ratio & 62.5 & 200 \\
\hline Specific gravity & 78.4 & 1.3 \\
\hline $\begin{array}{c}\text { Elastic modulus } \\
(\mathrm{GPa})\end{array}$ & 210 & 40 \\
\hline $\begin{array}{c}\text { Tensile strength } \\
(\mathrm{MPa})\end{array}$ & 1100 & 800 \\
\hline Fiber geometry & Hooked-end & Straight \\
\hline Fiber cross-section & Circular & Circular \\
\hline \multicolumn{2}{|c|}{}
\end{tabular}
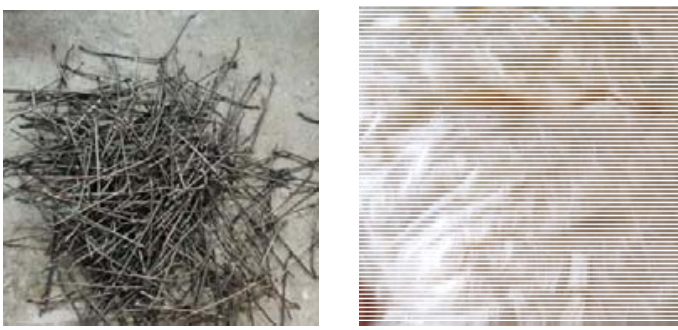

Figure $1 \mathrm{HS}$ and PVA fibers

\subsection{Mix proportion}

Mix proportions are taken as per $\mathrm{kg} / \mathrm{m}^{3}$. The mixes are designed matching to the strength of the low, medium, and high. After multiple trails, the final blend is completed. M30 is conceived permitting to the codebook IS 10262: 2019 [13]. The ratio is given in table 2

Table 2 Mix proportion of M30

\begin{tabular}{|l|l|}
\hline $\begin{array}{l}\text { Grade of } \\
\text { concrete }\end{array}$ & M30 \\
\hline Cement & 300 \\
\hline Fly Ash & 100 \\
\hline Fine aggregate & 651.08 \\
\hline Coarse aggregate & 1172 \\
\hline Water & 180 \\
\hline
\end{tabular}

\subsection{Casting and curing of specimens}

Casting specimen is the important part in the tests which are conducted here different specimens. Firstly, the materials are measured and collected according to the requirement then the materials are mixed as dry which is called a dry mix, and later water and superplasticizer are added according to the measurement which gives wet mix [14]. Then the moulds are taken and kept at a certain place. Waste oil or grease is applied to the mould which helps for easy removal of specimen after the dry [15]. Then the mix is placed in the specimen and left till 1 day later the moulds are taken and kept in curing for 28days. In between the specimens are tested for 3, 14, and 28 days, and outputs are given by few tests [16]

Table 3 specimens and their measurements

\begin{tabular}{|c|c|c|}
\hline $\begin{array}{c}\text { Strength Property } \\
\text { Compressive } \\
\text { strength }\end{array}$ & Cubecimen & Dimensions \\
\hline $\begin{array}{c}150 \times 150 \times 150 \\
\mathrm{~mm}\end{array}$ \\
\hline $\begin{array}{c}\text { Flexural Strength } \\
\text { Split tensile } \\
\text { strength }\end{array}$ & Prism & $\begin{array}{c}500 \times 100 \times 100 \\
\mathrm{~mm}\end{array}$ \\
\hline
\end{tabular}

\subsection{Experimental methods}

For HFRC moulds tests are conducted in certain experiments which are compressive strength test, split tensile strength test, and flexural strength test. the outputs are taken by the equipment. Compressive strength test the standard size of the cube is about $150 \times 150 \times 150 \mathrm{~mm}$ were taken [17]. Different mixes are casted and taken for the cube tests. The cubes are placed in a compressive strength test machine as shown in fig 2 and the load is applied about $14 \mathrm{~N} / \mathrm{mm} 2$ according to the standard codebook which is IS 516: 1959(BIS- 1959) [18]. The load capacity is taken $3000 \mathrm{kN}$ is applied. The tensile test has a particular standard specimen which is $300 \times 150 \mathrm{~mm}$ which is cylinder are taken according to 
the codebook IS 516: 1959 (BIS- 1959). The specimens are kept in the machine and a certain load is applied at the load capacity of $3000 \mathrm{kN}$ and the split tensile strength test maximum load is about $14 \mathrm{~N} / \mathrm{mm}^{2}$ [19] as shown in the fig 3 . The flexural strength test specimen of the prism is $500 \times 100 \times 100 \mathrm{~mm}$ which is used for the flexural strength testas fig 4 . Here the specimen is taken and placed in the machine and 4 point loading is done for tests and the load is applied $100 \mathrm{kN}$ and the upper twoline has space up to $13.2 \mathrm{~cm}$ separately [20]. The applied load on mould is considered according to the maximum level [21].

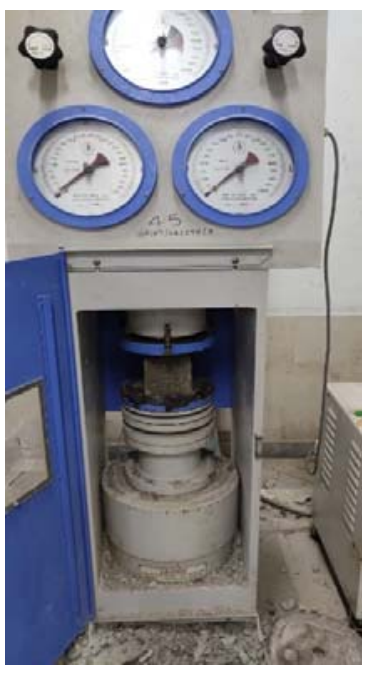

Figure 2 Compressive strength test

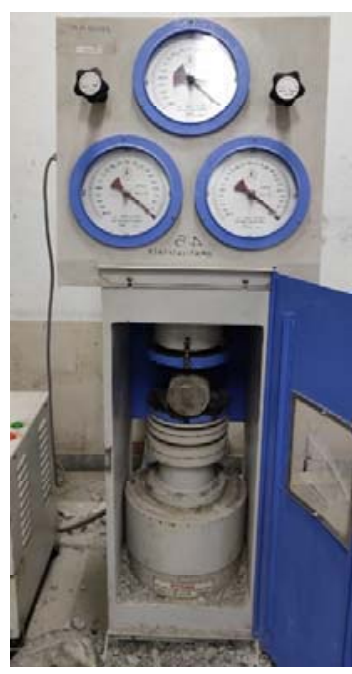

figure 3 Split tensile strength test

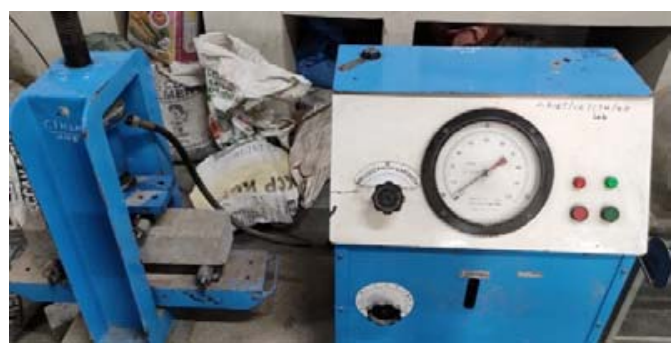

Figure 4 Flexural strength test

\section{Results and discussions}

\subsection{Mechanical properties of mono fiber concrete (FRC)}

This chapter gives information about the Mono fibers and hybrid fiber of PVA polyvinyl alcohol and HS Hooked end steel which makes a great combination for gaining good strength, ductility, and cracks of the specimen. Here the below table 4 gives results about mono fiber concrete which specimens are taken in different ratios and tests are conducted on it which are compressive strength test, split tensile test, and flexural strength test where the specimens are cube, cylinder, and prism and have different measurements. The ratios are about CM, PVA 0.05, PVA 0.1, PVA 0.15, PVA 0.2, HS 0.5 , and comparing to the Control mix (CM) we got a good result in the ratio of PVA 0.15 and HS 0.5 is considered [22]. Compressive strength test is conducted by the cube specimen which has $150 \times 150 \times 150 \mathrm{~mm}$ of sizes as per IS codebook and the unit of a test is in $\mathrm{N} / \mathrm{mm} 2$ or $\mathrm{kN}$ [23]. The above graph and tables give information about the strength effectiveness of the mixes [24]. The graph is represented with a color variation where blue gives the result about compressive strength test, orange gives result about split tensile strength test and ash color gives result about flexural strength test in this experiment. PVA 0.15 has good strength and deems hybrid fiber reinforcement concrete as mono fiber and the other fiber is HS hooked end steel. The loading rate is about $14 \mathrm{~N} / \mathrm{mm}^{2} / \mathrm{min}$ and there is a specific limit of combining PVA if there is any overdosage the value strength gets decreased by $0.2 \%$. The split tensile strength test is related to the control mix and compared with ratios of fiber reinforced concrete. The above graph and table give the result of strength effectiveness in the split tensile test. The units of strength test are in $\mathrm{N} / \mathrm{mm}^{2}$ or $\mathrm{kN}$ and the good result is given by the ratio PVA 0.15 and HS 0.5 . The split tensile test loading rate is about 1.2-2.4 N/mm $2 / \mathrm{min}$ and adding the PVA has its limits if the overdosage is done then the strength decreases to $0.2 \%$. Flexural strength test the mono fiber concrete specimens give the information in different ratio mixes [24]. the above graph and tables give the results conducted in 4 point loading. The ratio 0.15 and HS $0.5 \%$ are considered for hybrid reinforcement concrete mix. The units of the flexural strength test are in $\mathrm{N} / \mathrm{mm} 2$ or $\mathrm{kN}$. The ash color in the graph gives the result of the flexural test and here the loading rate value is about $1.2-2.4 \mathrm{~N} / \mathrm{mm} 2 / \mathrm{min}$ and the addition of PVA has certain limits if the limit is in overdosage then the strength gets decreased by $0.2 \%$.

The effectiveness of different mono fibers in the concrete of PVA and HS are in tests compressive, tensile, and flexural strength tests. Comparing all tests compressive strength test gives good strength effectiveness [25]. Considering the above graph and table results PVA0.15 and HS0.5\% are considered for hybrid fibers. The strength effectiveness is shown in the below table 4 and graph in fig 5 .

Table 4 Mechanical Properties of Mono Fiber Concrete

\begin{tabular}{|c|c|c|c|c|c|c|}
\hline \multirow{2}{*}{ Mix ID } & \multicolumn{2}{|c|}{ Compressive Strength (MPa) } & \multicolumn{2}{c|}{ Split Tensile Strength (MPa) } & \multicolumn{2}{c|}{ Flexural Strength (MPa) } \\
\hline & fck & $\begin{array}{c}\text { Strength } \\
\text { effectiveness (\%) }\end{array}$ & fst & $\begin{array}{c}\text { Strength } \\
\text { effectiveness (\%) }\end{array}$ & $f_{\text {ft }}$ & $\begin{array}{c}\text { Strength } \\
\text { effectiveness (\%) }\end{array}$ \\
\hline $\mathrm{CM}$ & 36.9 & - & 2.5 & - & 4.3 & - \\
\hline
\end{tabular}




\begin{tabular}{|l|l|l|l|l|l|l|} 
PVA 0.05 & 37.6 & 2 & 2.63 & 5.3 & 4.58 & 6.5 \\
\hline PVA 0.1 & 38.0 & 3.1 & 2.67 & 6.6 & 4.87 & 13.2 \\
\hline PVA 0.15 & 39.2 & 6.1 & 2.81 & 12.5 & 4.98 & 15.7 \\
\hline PVA 0.2 & 38.1 & 3.3 & 2.71 & 8.2 & 4.78 & 11.1 \\
\hline HS 0.5 & 38.4 & 4.2 & 2.78 & 11.1 & 4.95 & 15 \\
\hline $\begin{array}{l}\text { Nomenclature } \\
\text { "CM" Represents the control mix of plane concrete which gives strength effectiveness of Compressive strength, Split tensile }\end{array}$ \\
$\begin{array}{l}\text { strength, and Flexural strength. } \\
\text { "PVA 0.05" Represents Polyvinyl alcohol which has 0.05\% of PVA ratio in Mono fiber concrete. } \\
\text { "PVA 0.1" Represents Polyvinyl alcohol which has a 0.1\% of PVA ratio in Mono fiber concrete. } \\
\text { "PVA 0.15" Represents Polyvinyl alcohol which has a 0.15\% ratio in Mono fiber concrete. } \\
\text { "PVA 0.2" Represents Polyvinyl alcohol which has a 0.2\% ratio in Mono fiber concrete. } \\
\text { "HS 0.5" Represents Hooked-end steel which has a 0.5\% ratio in Mono fiber concrete. }\end{array}$ \\
\hline
\end{tabular}

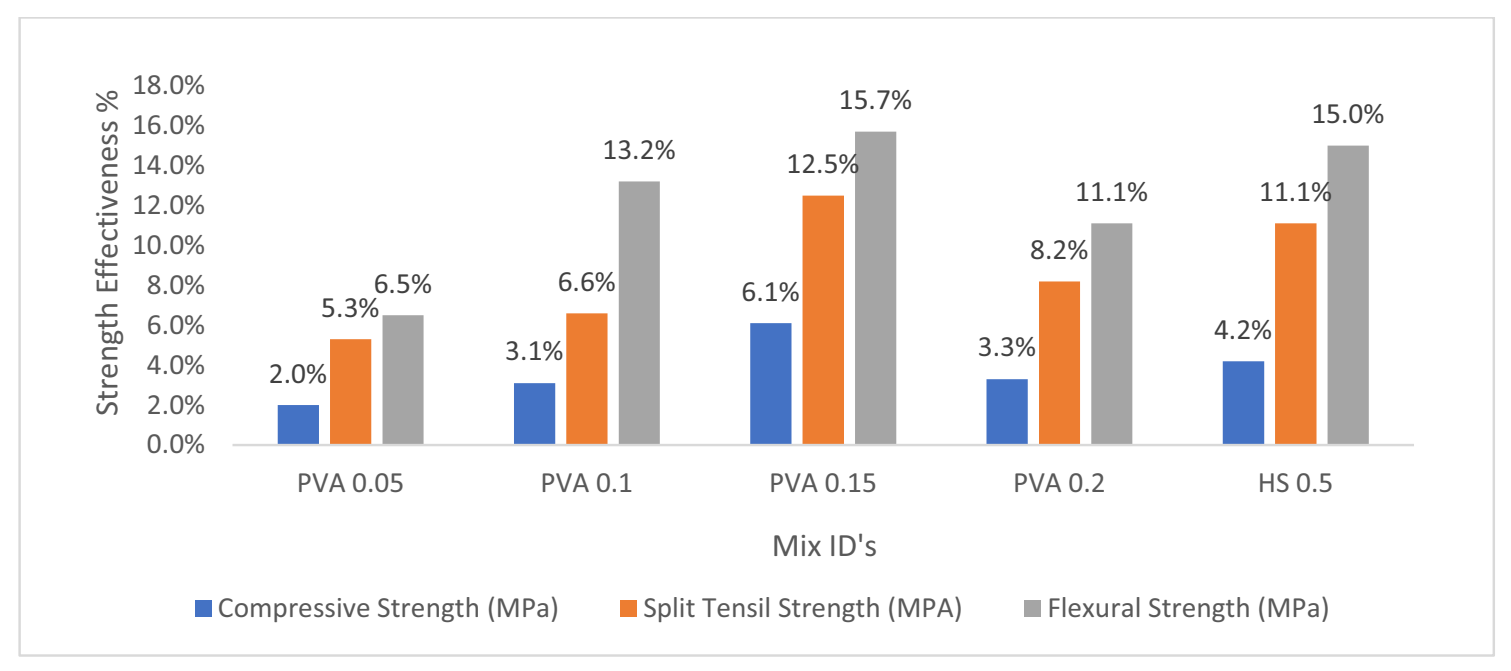

Figure 5 Strength Effectiveness of Mono Fiber Reinforced Concrete

\subsection{Mechanical properties of hybrid concrete}

From the above results of mono fiber concrete, we consider the ratio of PVA 0.15 and HS $0.5 \%$ values and taken as hybrid concrete. Considering the principles of the hybrid concrete rules we have 2 principles which are short, long, and metal and non-metallic fibers. These fibers have different shapes, sizes, and properties that are mechanical and physical [25]. There are different mix ratio's which are PVA $0.15 \%$ in ratio ,HS is $0.5 \%$, $0.45 \mathrm{HS}+0.05 \mathrm{PVA}, 0.4 \mathrm{HS}+0.1 \mathrm{PVA}, 0.35 \mathrm{HS}+$ $0.15 \mathrm{PVA}, 0.3 \mathrm{HS}+0.2 \mathrm{PVA}$. The HFRC tests are about compressive strength test, split tensile strength test, and flexural strength test and we compare the tests for getting good strength effectiveness results. Here blue, orange and ash colors represent the results of three compressive, split tensile, and flexural strength tests Compressive strength test the HFRC mixes has certain limits to maintain good strength if there is any overdosage the strength gets decreased so maintain of limits is a crucial role in the mix. The results of compressive strength test in HFRC is taken in different ratio mix's which are in $0.45 \mathrm{HS}+0.05 \mathrm{PVA}, 0.4 \mathrm{HS}+$ $0.1 \mathrm{PVA}, 0.35 \mathrm{HS}+0.15 \mathrm{PVA}$ and $0.3 \mathrm{HS}+0.2 \mathrm{PVA}$. Among these mix's $0.35 \mathrm{HS}+0.15 \mathrm{PVA}$ gives good strength effectiveness in HFRC and the where the 0.3HS is hooked end steel \% and 0.15PVA is polyvinyl alcohol. The blue color percentage in the graph gives all the results about the compressive strength test in different mix ratios. the result is about considering $7 \%$ of dosage in HFRC. show the results of a split tensile test in orange color percentage Split tensile strength test units is about $\mathrm{N} / \mathrm{mm} 2$ or $\mathrm{kN}$. The specimen is in cylinder shape of measurements $300 \times 150 \mathrm{~mm}$. Here mix's $0.35 \mathrm{HS}+0.15 \mathrm{PVA}$ is considered as a good ratio which gives suitable strength of HFRC comparing with other mix ratios [26]. After a lot of trials, $24.3 \%$ of strength is good comparing with other percentages is considered. The HFRC acts as a bridge between the internal or 
external cracks of the specimen [26]. By HFRC crack growth and brittleness are controlled and the strength of the concrete is increased. Flexural strength test HFRC contains both metallic and non-metallic fibers which are PVA and Hooked end steel. From the mono fiber values, certain mix ratios are taken and mixes are divided and cast later on the flexural strength test is conducted on every specimen which has different mix's which are $0.45 \mathrm{HS}+0.05 \mathrm{PVA}, 0.4 \mathrm{HS}+0.1 \mathrm{PVA}, 0.35 \mathrm{HS}+$ $0.15 \mathrm{PVA}$, and $0.3 \mathrm{HS}+0.2 \mathrm{PVA}$. among this mix's $0.35 \mathrm{HS}+0.15 \mathrm{PVA}$ gives the best result in the flexural strength test and gains a good amount of strength. After several trials, this mix is declared the effective strength mix. Based on the limits and conditions these are designed as a specimen. The above graph and table show the results which are occurred. Here ash color percentage is represented as flexural strength test, and this plays a major role in getting a good amount of crack control and brittleness in HFRC specimen. The strength effectiveness of HFRC in concrete mix's non-metallic and metallic fibers which are PVA and HS are taken as fibers for HFRC. The mixes are designed according to the strength effectiveness. The mono fiber concrete value is taken and designed for HFRC where the mix id of mono is PVA $0.15 \%$, and HS $0.5 \%$ is considered. Later on the mix's are $0.45 \mathrm{HS}+0.05 \mathrm{PVA}, 0.4 \mathrm{HS}+$ $0.1 \mathrm{PVA}, 0.35 \mathrm{HS}+0.15 \mathrm{PVA}$ and $0.3 \mathrm{HS}+0.2 \mathrm{PVA}$ are taken and compared with the control mix after all the experiments are tested with various trails the strength effectiveness is good at one mix id which is $0.35 \mathrm{HS}+$ 0.15 PVA where the results are Compressive strength test is $7 \%$, Split tensile strength test is $24 \%$, Flexural strength test is $39.20 \%$ respectively. Here the graph is represented in different colors where blue color is about compressive strength test, the orange color is about split tensile strength test and ash color is about flexural strength test. HFRC can give strength to the specimen and controls the crack growth and brittleness [27]. Strength effectiveness of hybrid fibers are shown in the below table 5 and fig 6 .

Table 5 Mechanical Properties of HFRC

\begin{tabular}{|c|c|c|c|c|c|c|}
\hline \multirow[t]{2}{*}{ Mix ID } & \multicolumn{2}{|c|}{ Compressive Strength (MPa) } & \multicolumn{2}{|c|}{ Split Tensile Strength (MPa) } & \multicolumn{2}{|c|}{ Flexural Strength (MPa) } \\
\hline & fck & $\begin{array}{l}\text { Strength } \\
\text { effectiveness (\%) }\end{array}$ & fst & $\begin{array}{c}\text { Strength } \\
\text { effectiveness (\%) }\end{array}$ & $\mathrm{fft}$ & $\begin{array}{c}\text { Strength } \\
\text { effectiveness (\%) }\end{array}$ \\
\hline $\mathrm{CM}$ & 36.9 & - & 2.5 & - & 4.3 & - \\
\hline PVA 0.15 & 39.2 & 6.1 & 2.81 & 12.5 & 4.98 & 15.7 \\
\hline HS 0.5 & 38.4 & 4.2 & 2.74 & 9.6 & 4.83 & 12.3 \\
\hline $0.45 \mathrm{HS}+0.05 \mathrm{PVA}$ & 38.8 & 5.2 & 2.83 & 13.2 & 5.04 & 17.3 \\
\hline $0.4 \mathrm{HS}+0.1 \mathrm{PVA}$ & 39.4 & 6.9 & 2.89 & 15.6 & 5.27 & 22.5 \\
\hline $0.35 \mathrm{HS}+0.15 \mathrm{PVA}$ & 39.5 & 7 & 3.11 & 24.3 & 5.99 & 39.2 \\
\hline $0.3 \mathrm{HS}+0.2 \mathrm{PVA}$ & 38.8 & 5.2 & 2.81 & 12.5 & 5.48 & 27.5 \\
\hline \multicolumn{7}{|c|}{$\begin{array}{l}\text { Nomenclature } \\
\text { "CM" Represents the control mix of plane concrete which gives strength effectiveness of Compressive strength, Split tensile } \\
\text { strength, and Flexural strength. } \\
\text { "PVA } 0.15 " \text { Represents Polyvinyl alcohol which has a } 0.15 \% \text { ratio in Mono fiber concrete. } \\
\text { "HS 0.5" Represents Hooked-end steel which has a } 0.5 \% \text { ratio in Mono fiber concrete. } \\
\text { "0.45HS + 0.05PVA" Represents the hybrid fiber combination }(0.45 \mathrm{HS} \%+0.05 \mathrm{PVA} \%) \text { at total fiber volume } \\
\text { "0.4HS + 0.1PVA" Represents the hybrid fiber combination }(0.4 \mathrm{HS} \%+0.1 \mathrm{PVA} \%) \text { at total fiber volume } \\
\text { "0.35HS + 0.15PVA" Represents the hybrid fiber combination }(0.35 \mathrm{HS} \%+0.15 \mathrm{PVA} \%) \text { at total fiber volume } \\
\text { "0.3HS + 0.2PVA" Represents the hybrid fiber combination }(0.3 \mathrm{HS} \%+0.2 \mathrm{PVA} \%) \text { at total fiber volume }\end{array}$} \\
\hline
\end{tabular}




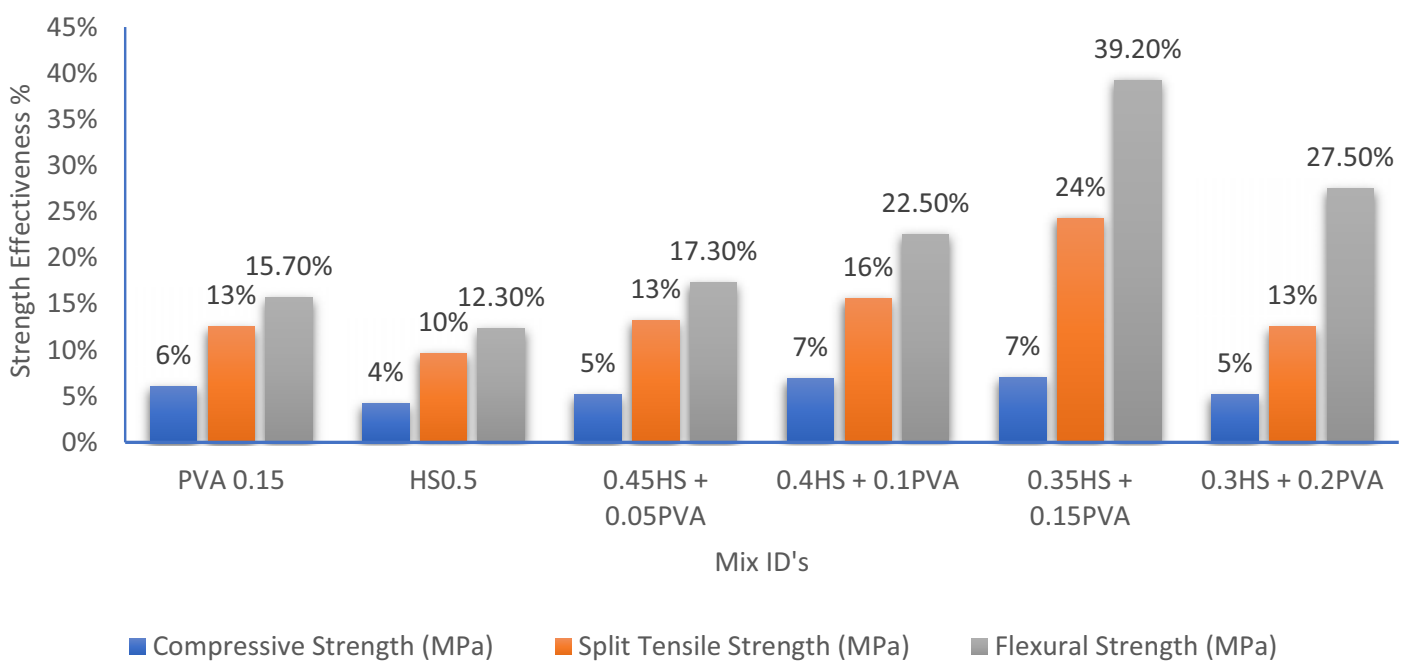

Figure 6 Strength Effectiveness of HFRC

\section{Conclusions}

The mechanical properties of HFRC specimen tests like compressive strength test, split tensile strength and flexural strength and their strength effectiveness of hybrid fibers are studied. The outputs and discussion are concluded below

- The optimum dosage of metallic and nonmetallic fibers of PVA and HS fibers are good at the dosage $0.15 \% \mathrm{PVA}$ and $0.5 \% \mathrm{HS}$.

- Mono fiber PVA has shown good effective strength results comparing with $\mathrm{HS}$ fiber.

- Hybridization of fibers with a combined ratio of $0.35 \mathrm{HS}+0.15 \mathrm{PVA}$ gave better results in strength compared with other ratios.

- Considering all three tests which are compressive strength, flexural, and split tensile strength effectiveness in compressive strength test is effective.

- Hybrid fiber which is a combination of nonmetallic and metallic fibers which are PVA and $\mathrm{HS}$ fibers acts as the bridge between the micro and macro cracks and gives strength to the HFRC and improves the toughness of concrete and tensile strength.

\section{References}

1. Chen, Bo, and Wenjia Liu. "Mobile agent computing paradigm for building a flexible structural health monitoring sensor network." Computer-Aided Civil and Infrastructure Engineering 25.7 (2010): 504-516.
2. Dworakowski, Ziemowit, et al. "Vision-based algorithms for damage detection and localization in structural health monitoring." Structural Control and Health Monitoring 23.1 (2016): 35-50.

3. Sony, Sandeep, Shea Laventure, and Ayan Sadhu. "A literature review of next-generation smart sensing technology in structural health monitoring." Structural Control and Health Monitoring 26.3 (2019): e2321.

4. Pham, Thong M., and Hong Hao. "Behavior of fiberreinforced polymer-strengthened reinforced concrete beams under static and impact loads." International Journal of Protective Structures 8.1 (2017): 3-24.

5. Klyuev, Sergey V., et al. "Experimental study of fiber-reinforced concrete structures." Materials Science Forum. Vol. 945. Trans Tech Publications Ltd, 2019.

6. Kang, Min-Chang, Doo-Yeol Yoo, and Rishi Gupta. "Machine learning-based prediction for compressive and flexural strengths of steel fiber-reinforced concrete." Construction and Building Materials 266 (2021): 121117.

7. Siddiqui, Nadeem A., et al. "Reliability Assessment of HFRC Slabs Against Projectile Impact." International Journal of Concrete Structures and Materials 12.1 (2018): 1-11.

8. Sharma, Raju, and Prem Pal Bansal. "Behavior of RC exterior beam column joint retrofitted using UHPHFRC." Construction and Building Materials 195 (2019): 376-389.

9. Yao, Wenjin, et al. "Blast-resistant performance of hybrid fiber-reinforced concrete (hfrc) panels subjected to contact detonation." Applied Sciences 10.1 (2020): 241.

10. Junwei, Zhang, Li Shijie, and Peng Hongjian. "Experimental investigation of multiscale hybrid fibres on the mechanical properties of high-performance 
concrete." Construction and Building Materials 299 (2021): 123895.

11. Koniki, Srikanth, et al. "Mechanical behavior of triple-blended hybrid fiber-reinforced concrete: an experimental and numerical study." Innovative Infrastructure Solutions 6.3 (2021): 1-14.

12. Banthia, Nemkumar, et al. "Fiber synergy in Hybrid Fiber Reinforced Concrete (HyFRC) in flexure and direct shear." Cement and Concrete Composites 48 (2014): 91-97.

13. Nguyen, Wilson, et al. "Electrochemical polarization and impedance of reinforced concrete and hybrid fiber-reinforced concrete under cracked matrix conditions." Electrochimica Acta 271 (2018): 319-336.

14. Sun, Linzhu, et al. "Stress strain behavior of hybrid steel-PVA fiber reinforced cementitious composites under uniaxial compression." Construction and Building Materials 188 (2018): 349-360.

15. Shaaban, Ibrahim G., et al. "Experimental and theoretical behaviour of reinforced concrete beams containing hybrid fibres." Structures. Vol. 32. Elsevier, 2021.

16. Li, K. F., et al. "Effects of hybrid fibers on workability, mechanical, and time-dependent properties of high strength fiber-reinforced self-consolidating concrete." Construction and Building Materials 277 (2021): 122325.

17. Said, Mohamed, et al. "Experimental and analytical investigation of high performance concrete beams reinforced with hybrid bars and polyvinyl alcohol fibers." Construction and Building Materials 259 (2020): 120395

18. Liu, Fangyu, Wenqi Ding, and Yafei Qiao. "Experimental investigation on the tensile behavior of hybrid steel-PVA fiber reinforced concrete containing fly ash and slag powder." Construction and Building Materials 241 (2020): 118000.

19. Li, Yi, et al. "Pore structure and splitting tensile strength of hybrid Basalt-Polypropylene fiber reinforced concrete subjected to carbonation." Construction and Building Materials 297 (2021): 123779.

20. Koniki, Srikanth, and D. Ravi Prasad. "Mechanical properties and constitutive stress-strain behaviour of steel fiber reinforced concrete under uni-axial stresses." Journal of Building Pathology and Rehabilitation 4.1 (2019): 1-8.

21. Fares, Galal, Mahmoud Hamad Albaroud, and M. Iqbal Khan. "Fine limestone dust from ornamental stone factories: a potential filler in the production of HighPerformance Hybrid Fiber-Reinforced Concrete." Construction and Building Materials 262 (2020): 120009.

22. Koniki, Srikanth, and D. Ravi Prasad. "Influence of hybrid fibres on strength and stress-strain behaviour of concrete under uni-axial stresses." Construction and Building Materials 207 (2019): 238-248..
23. Koniki, Srikanth, and P. D. Ravi. "A study on mechanical properties and stress-strain response of high strength concrete reinforced with polypropylenepolyester hybrid fibres." Cement, Wapno, Beton 1 (2018): 67-77.

24. Özkan, Şükrü, and Fuat Demir. "The hybrid effects of PVA fiber and basalt fiber on mechanical performance of cost effective hybrid cementitious composites." Construction and Building Materials 263 (2020): 120564.

25. Teng, Susanto, Vahid Afroughsabet, and Claudia P. Ostertag. "Flexural behavior and durability properties of high performance hybrid-fiber-reinforced concrete." Construction and Building Materials 182 (2018): 504-515

26. Son, Minjae, et al. "Effects of the strain rate and fiber blending ratio on the tensile behavior of hooked steel fiber and polyvinyl alcohol fiber hybrid reinforced cementitious composites." Cement and Concrete Composites 106 (2020): 103482.

27. Pakravan, H. R., M. Latifi, and M. Jamshidi. "Hybrid short fiber reinforcement system in concrete: A review." Construction and building materials 142 (2017): 280-294. 